\title{
QUALIDADE DE SEMENTES DE CULTIVARES PRECOCES DE SOJA PRODUZIDAS EM TRÊS ÉPOCAS'
}

\author{
ELAINY BOTELHO CARVALHO PEREIRA ${ }^{2}$, AILTON VITOR PEREIRA ${ }^{3}$ e ANTÔNIO CARLOS FRAGA ${ }^{4}$
}

\begin{abstract}
RESUMO - O trabalho foi conduzido na região de Goiânia, com o objetivo de avaliar a qualidade fisiológica e sanitária das sementes de sete cultivares precoces de soja (EMGOPA 304, EMGOPA 309 , EMGOPA 316, EMBRAPA 1, EMBRAPA 4, Rainha e Itiquira), produzidas em três épocas de semeadura (convencional, em 20/11; antecipada, em 30/10; e retardada, em 30/12/1995). O delineamento experimental foi de blocos casualizados, com três repetições, em esquema de parcelas subdivididas. A qualidade fisiológica foi avaliada com base na germinação em rolo de papel e em areia e no vigor, pelo teste de tetrazólio, enquanto a sanidade foi avaliada pelo teste do papel de filtro. Os resultados obtidos permitem concluir que: a qualidade fisiológica e sanitária das sementes é influenciada pelas cultivares e épocas de semeadura; a qualidade das sementes produzidas na semeadura antecipada para o final de outubro é afetada por condições adversas de umidade, danos mecânicos e incidência de patógenos, especialmente Phomopsis sojae, enquanto na semeadura retardada para o final de dezembro é afetada por danos mecânicos.
\end{abstract}

Termos para indexação: Glycine max, interação genótipo-ambiente, capacidade germinativa, época de semeadura.

\section{SEED QUALITY OF EARLY MATURING SOYBEAN CULTIVARS FROM DIFFERENT SOWING DATES}

\begin{abstract}
This work aimed to evaluate the physiological and sanitary seed qualities of seven early maturing soybean cultivars (EMGOPA 304, EMGOPA 309, EMGOPA 316, EMBRAPA 1, EMBRAPA 4, Rainha and Itiquira), obtained from three sowing dates (conventional, on Nov. 20; early, on Oct. 30; and delayed, on Dec. 30/1995), at Goiânia, GO, Brazil. The experiment was carried out in split plot and randomized complete block design, with three replications. Physiological quality was evaluated by germination test in rolled paper and in sand seed bed and by seed vigor through the tetrazolium test. Sanitary quality was evaluated by means of the Blotter test. The results showed that physiological and sanitary seed qualities are influenced by the cultivars and the sowing dates. Early sowing in October results in seed quality losses caused by the adverse environment moisture conditions and the threshing mechanical damages, allied to the occurrence of seed pathogen infection, specially Phomopsis sojae. High threshing mechanical damages are the cause of seed quality losses in the delayed sowing at the end of December.
\end{abstract}

Index terms: Glycine max, genotype environment interaction, germinability, sowing date.

${ }^{1}$ Aceito para publicação em 13 de dezembro de 1999.

Trabalho extraído da tese de doutorado apresentada pelo primeiro autor à Universidade Federal de Lavras (UFLA), MG.

${ }^{2}$ Eng. Agrôn., Dra., EMATER-Goiás, Caixa Postal 331, CEP 70610-060 Goiânia, GO.

${ }^{3}$ Eng. Agrôn., Dr., Embrapa-Centro de Pesquisa Agropecuária dos Cerrados (CPAC), Caixa Postal 08223, CEP 70301-970 Planaltina, DF. E-mail: ailton@cpac.embrapa.br

${ }^{4}$ Eng. Agrôn., Dr., Dep. de Agricultura, UFLA, Caixa Postal 37, CEP 37200-000 Lavras, MG.

\section{INTRODUÇÃO}

Na maior parte da região dos Cerrados do Brasil Central, as condições climáticas não são favoráveis à produção de sementes de soja de boa qualidade, principalmente das cultivares de ciclo precoce, cujas fases de maturação e colheita coincidem com períodos de altas temperaturas e chuvas intensas (França Neto et al., 1990). Este fato tem levado à produção e rejeição de lotes de sementes com qualidade inferior 
aos padrões mínimos exigidos e, em alguns casos, à adoção de padrões inferiores de qualidade, admitindo-se valores de germinação de 75\%, no Estado de Goiás (Embrapa, 1996).

A qualidade fisiológica das sementes de soja é controlada geneticamente e, portanto, inerente a cada genótipo; este fator é preponderante em relação às práticas de manejo da cultura (Krzyzanowski et al., 1993). Segundo os autores, caracteres da planta, da vagem, da própria semente de soja e seus efeitos interativos podem estar relacionados com a deterioração das sementes, determinando o comportamento diferencial entre genótipos e seu grau de tolerância à deterioração das sementes em função das condições de campo e da colheita mecanizada. Assim, todos os mecanismos que dificultam a penetração de água e patógenos nas sementes podem ser benéficos à sua qualidade.

Diferentes épocas de semeadura proporcionam diferentes condições de ambiente, sob as quais a cultura da soja se desenvolve, completa a maturação das sementes, e é colhida. Efeitos significativos das épocas de semeadura sobre os principais caracteres agronômicos e as qualidades fisiológica e sanitária das sementes de soja foram constatados por Nunes Júnior (1984), Bhering (1989), Urben Filho \& Souza (1993) e Costa et al. (1995).

Segundo França Neto \& Henning (1992), a deterioração das sementes de soja resulta da interação de processos e alterações físicas, fisiológicas e sanitárias. Assim, os autores propõem o diagnóstico completo de sua qualidade (DIACOM) através da combinação dos testes de germinação em rolo de papel e em areia, de vigor pelo teste de tetrazólio e de sanidade pelo teste do papel de filtro.

Este trabalho teve como objetivo avaliar a qualidade fisiológica e sanitária das sementes de sete cultivares precoces de soja, obtidas a partir de três épocas de semeadura, na região de Goiânia.

\section{MATERIAL E MÉTODOS}

O trabalho compreendeu uma fase de campo, com a instalação e condução de um experimento até a colheita das sementes, e outra, de laboratório, para a avaliação da qualidade. $\mathrm{O}$ experimento de campo foi conduzido num Latossolo Vermelho-Escuro de textura argilosa e relevo suave ondulado, durante a safra 1995/96, na Estação Experimental da EMATER-GO, localizada a 20 km de Goiânia, e com latitude sul de $16^{\circ} 42^{\prime} 12^{\prime \prime}$, longitude de 49 $14^{\prime} 16^{\prime \prime}$ (W. Grw.) e altitude de $730 \mathrm{~m}$. O clima da região é do tipo Amig', segundo a classificação de Köppen. Os dados de temperatura e precipitação referentes ao período experimental são apresentados nas Figs. 1, 2 e 3. O preparo e correção do solo e o manejo da cultura foram feitos de acordo com as recomendações da Embrapa (1996), para a região central do Brasil.

O delineamento experimental foi de blocos casualizados, com três repetições, em esquema de parcelas subdivididas, testando nas parcelas as três épocas de semeadura (convencional, em 20/11; antecipada, em 30/10; e retardada, em 30/12/1995), e nas subparcelas, as sete cultivares precoces de soja (EMGOPA 304, EMGOPA 309, EMGOPA 316, EMBRAPA 1, EMBRAPA 4, Rainha e Itiquira). A subparcela foi constituída de quatro linhas de $5,0 \mathrm{~m}$ de comprimento e com espaços de $0,5 \mathrm{~m}$ entre si; a área útil foi constituída pelas duas linhas centrais, eliminando-se 0,5 m em cada extremidade (Mauro et al., 1995). A semeadura, feita em 20/11, foi tomada como testemunha, por ser representativa da época convencional recomendada para o plantio de soja no Estado de Goiás, que se estende de meados de novembro a meados de dezembro, segundo Embrapa (1996).

As plantas foram colhidas manualmente no estádio R8, isto é, quando apresentavam cerca de $95 \%$ das vagens com coloração amarelo-palha ou marrom. A trilha foi realizada mecanicamente em trilhadeira estacionária, e as sementes foram, posteriormente, embaladas em sacos de papel e acondicionadas em caixas de isopor, para o transporte ao laboratório de análise de sementes do Departamento de Agricultura da Universidade Federal de Lavras. A avaliação da qualidade das sementes foi feita com base na germinação em rolo de papel e em canteiro de areia e no vigor avaliado pelo teste de tetrazólio. A sanidade das sementes foi avaliada pelo teste do papel de filtro, segundo França Neto \& Henning (1992).

A análise de variância foi realizada transformando os dados em arco seno da raiz quadrada da porcentagem (Pimentel-Gomes, 1984) e utilizando o Sistema SANEST. As comparações entre médias foram efetuadas pelo teste de Tukey, a 5\% de probabilidade. Nos casos em que houve significância da interação entre épocas de semeadura e cultivares, foi feito o desdobramento da interação para verificar os efeitos de cultivar dentro de épocas de semeadura, $\mathrm{e}$ vice-versa. Os resultados do teste de sanidade e os danos letais causados por condições adversas de umidade, avaliados pelo teste de tetrazólio, não foram analisados, porque apresentaram variâncias muito heterogêneas entre os tratamentos. 


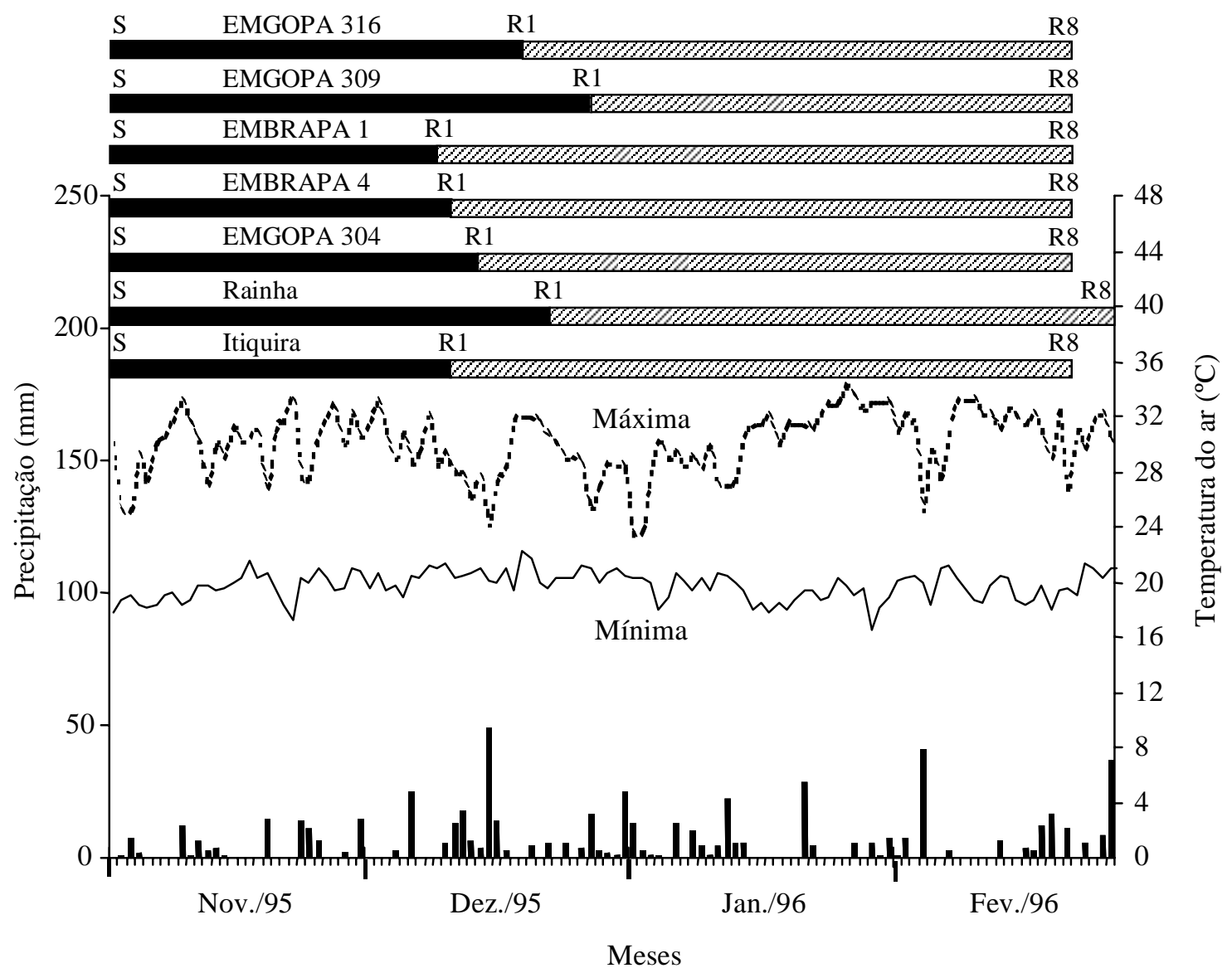

FIG. 1. Época de semeadura (30/10/95): ciclos culturais e estádios fenológicos das plantas de soja ( $\mathrm{S}$ = semeadura; $\mathrm{R} 1, \mathrm{R8}$ = estádios reprodutivos); dados diários de precipitação pluvial e de temperaturas máxima e mínima. Goiânia, GO.

\section{RESULTADOS E DISCUSSÃO}

Considerando a germinação das sementes em rolo de papel e canteiro de areia (Tabela 1), as cultivares EMGOPA 309 e Rainha mostraram-se mais estáveis, pois apresentaram germinação estatisticamente igual nas três épocas. Por outro lado, as demais cultivares produziram sementes com menor germinação, quando semeadas antecipadamente em 30/10. Na última época de semeadura, em 30/12, as cultivares EMGOPA 304 e EMGOPA 316 não mantiveram o mesmo nível de germinação constatado em 20/11.
Não houve diferença de germinação das sementes produzidas pelas cultivares nas épocas de $20 / 11$ e 30/12, nos dois métodos. No entanto, na época de $30 / 10$, valores superiores de germinação foram constatados nas cultivares Rainha, EMGOPA 309, EMGOPA 316 e EMBRAPA 304, em areia, e apenas no tocante à cultivar Rainha, em rolo de papel. Na semeadura de outubro, as cultivares EMBRAPA 1, EMBRAPA 4 e Itiquira produziram sementes com valores de germinação inferiores ao padrão mínimo de 75\% estabelecido para a comercialização, na safra de 1996/1997, no Estado de Goiás (Embrapa, 1996). 


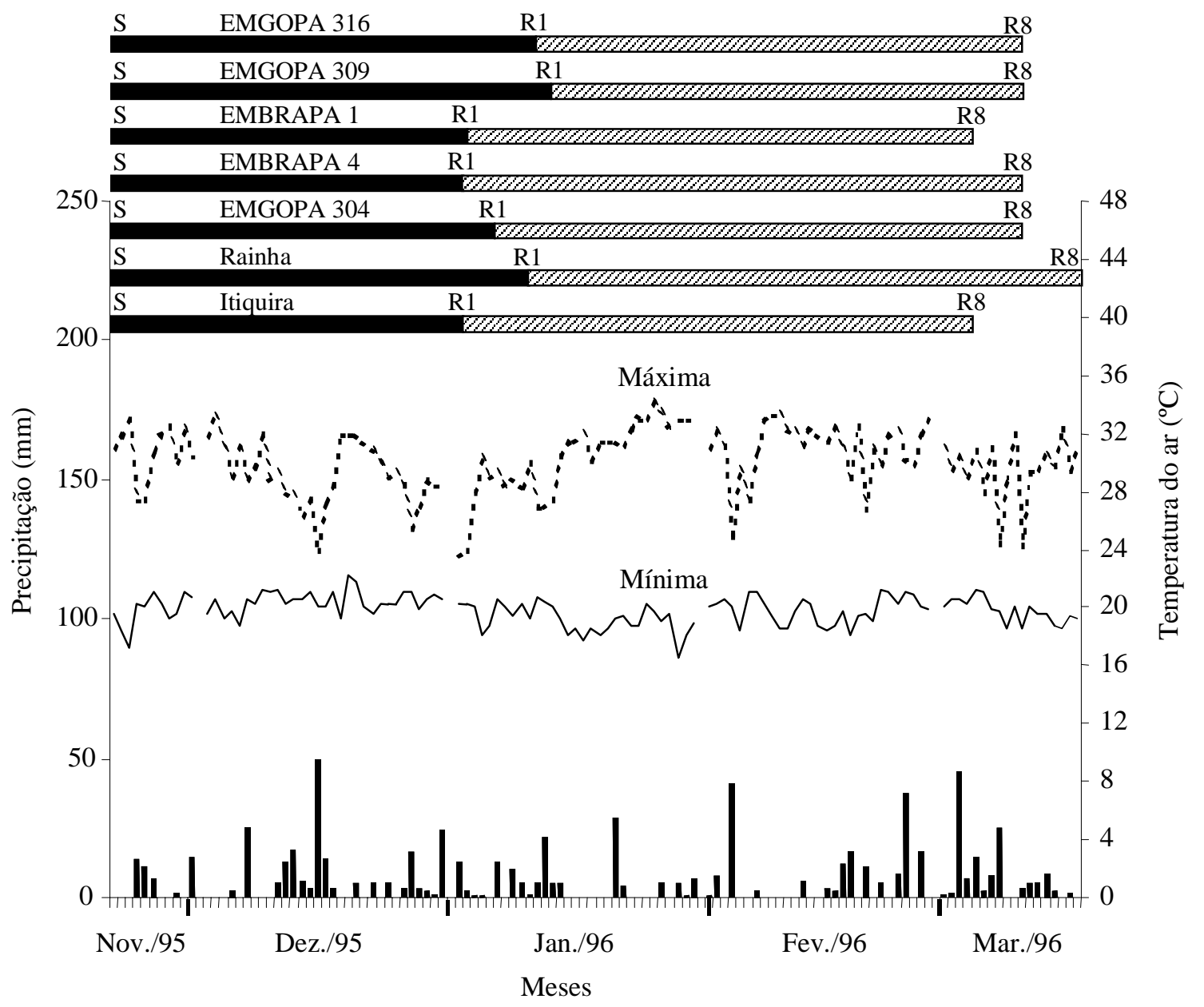

FIG. 2. Época de semeadura (20/11/95): ciclos culturais e estádios fenológicos das plantas de soja ( $\mathrm{S}$ = semeadura; $\mathrm{R} 1, \mathrm{R8}$ = estádios reprodutivos); dados diários de precipitação pluvial e de temperaturas máxima e mínima. Goiânia, GO.

Os valores de germinação em areia foram, geralmente, superiores aos obtidos em rolo de papel, e estão de acordo com os obtidos por França Neto \& Henning (1992), que constataram que a germinação das sementes em canteiro de areia ou no solo é menos afetada por fungos, especialmente Phomopsis spp., pois ficam restritos ao tegumento, e permanecem no substrato durante a emergência.

Analisando os resultados de vigor pelo teste de tetrazólio (Tabela 2), observa-se que as cultivares estudadas produziram sementes com máximo vigor quando semeadas em novembro, exceto a cultivar Itiquira, cujo vigor máximo foi obtido quando semeada mais tardiamente, em dezembro. A cultivar Rainha merece destaque especial, pela sua alta estabilidade, pois produz sementes de vigor muito alto quando semeada em outubro e novembro, e alto, em dezembro. Deve-se ressaltar, ainda, que a cultivar Rainha apresentou os maiores valores de vigor registrados nas três épocas de semeadura. A cultivar 


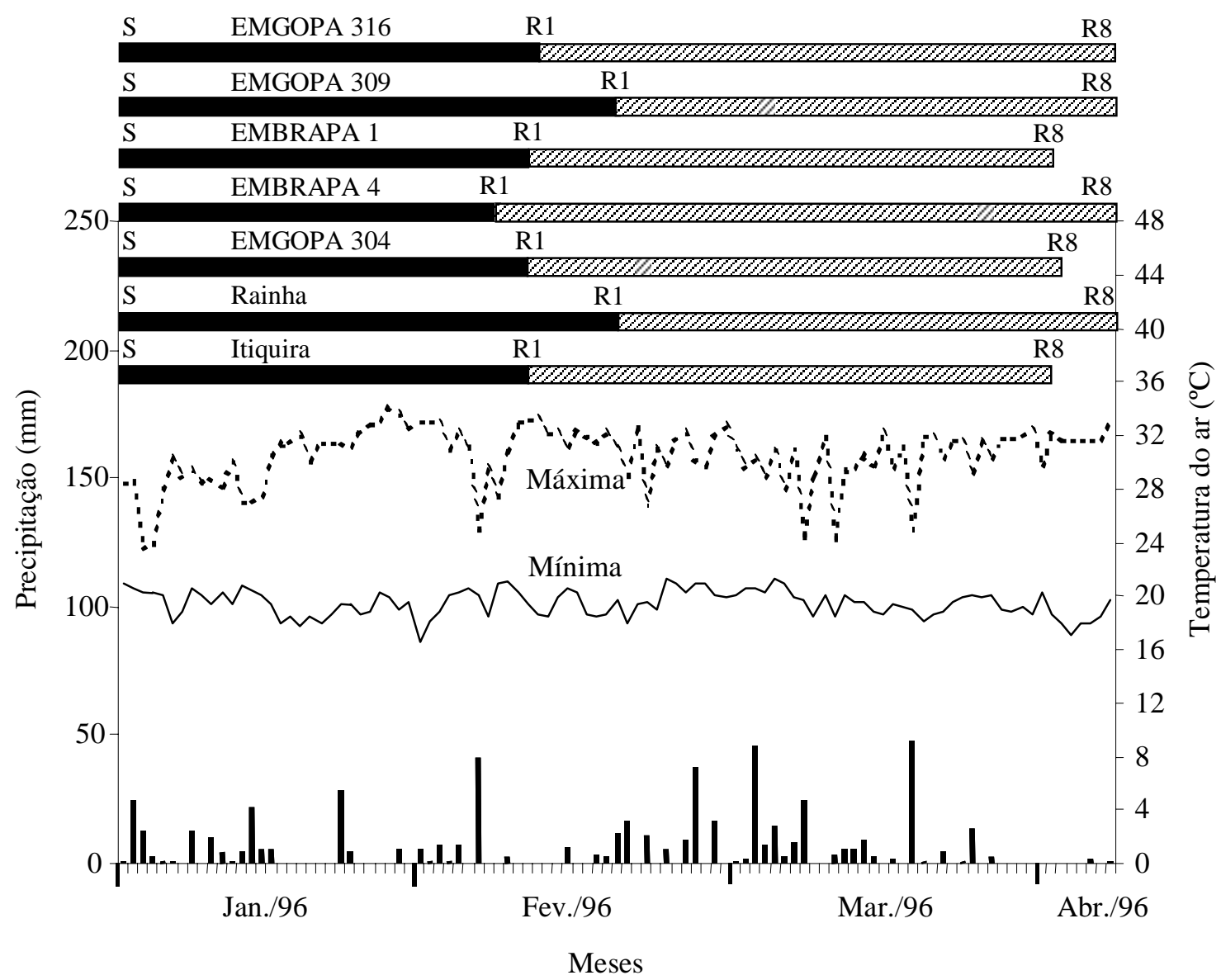

FIG. 3. Época de semeadura (30/12/95): ciclos culturais e estádios fenológicos das plantas de soja ( $\mathrm{S}=$ semeadura; $\mathrm{R} 1, \mathbf{R 8}$ = estádios reprodutivos); dados diários de precipitação pluvial e de temperaturas máxima e mínima. Goiânia, GO.

EMGOPA 309 foi também estável nas três épocas, porém, com nível médio de vigor das sementes.

O decréscimo do poder germinativo e do vigor em sementes produzidas nas semeaduras fora da época convencional, deve-se principalmente à maior incidência de danos mecânicos nas sementes provenientes da semeadura retardada para dezembro (Tabela 3), ou à deterioração das sementes oriundas da semeadura antecipada para outubro por condições adversas de umidade ( Tabela 4 e Fig. 1) aliada a alta incidência de Phomopsis sojae (Tabela 5). Entretanto, as cultivares apresentaram comportamento diferenciado quanto a essas variáveis nas três épocas de semeadura. A cultivar Rainha manteve altos níveis de vigor das sementes produzidas nas três épocas, em decorrência das menores incidências de danos mecânicos e de umidade. Mesmo com danos mecânicos totais de $42 \%$ e letais de $7 \%$, observados na época de 30/12, as sementes produzidas pela cultivar Rainha ainda apresentaram vigor alto, enquanto nas épocas de 30/10 e 20/11 as sementes apresentaram vigor muito alto.

$\mathrm{Na}$ semeadura antecipada para outubro, as demais cultivares produziram sementes com alta incidência de danos mecânicos totais $(55 \%$ a $71 \%)$ e letais ( $6 \%$ a $28 \%$ ), em relação aos $31 \%$ e $0,7 \%$ apre- 
sentados pela cultivar Rainha, respectivamente. Como referência, França Neto (1994) aponta como restrição a incidência de danos mecânicos letais de $7 \%$ a $10 \%$, e restrição séria quando maior que $10 \%$. Assim, as cultivares EMGOPA 316, EMGOPA 309, EMBRAPA 1, EMBRAPA 4 e Itiquira apresentaram restrições sérias quanto ao dano mecânico na pro- dução de sementes em lavouras semeadas antecipadamente. Na época convencional de semeadura em novembro, os danos mecânicos foram restritivos apenas quanto à produção de sementes das cultivares EMGOPA 309 e Itiquira. Na semeadura retardada para dezembro, os danos mecânicos foram restritivos no tocante às sementes das cultivares Rainha e

TABELA 1. Valores médios de porcentagem de germinação em rolo de papel e em canteiro de areia, de sementes de sete cultivares precoces de soja, produzidas a partir de três épocas de semeadura, na região de Goiânia, GO'.

\begin{tabular}{|c|c|c|c|c|c|c|}
\hline \multirow[t]{2}{*}{ Cultivares } & \multicolumn{3}{|c|}{ Germinação em rolo de papel $(\%)^{2}$} & \multicolumn{3}{|c|}{ Germinação em canteiro de areia $(\%)^{3}$} \\
\hline & $30 / 10 / 95$ & $20 / 11 / 95$ & $30 / 12 / 95$ & $30 / 10 / 95$ & $20 / 11 / 95$ & $30 / 12 / 95$ \\
\hline EMGOPA 316 & $81,00 \mathrm{bA}$ & $90,33 \mathrm{aA}$ & $85,67 \mathrm{aA}$ & $86,67 \mathrm{abB}$ & $98,33 \mathrm{aA}$ & $83,33 \mathrm{aB}$ \\
\hline EMGOPA 309 & $79,00 \mathrm{bA}$ & $87,00 \mathrm{aA}$ & $83,33 \mathrm{aA}$ & $89,67 \mathrm{aA}$ & $91,67 \mathrm{aA}$ & $89,33 \mathrm{aA}$ \\
\hline EMBRAPA 1 & $60,33 \mathrm{cdB}$ & $92,00 \mathrm{aA}$ & $93,00 \mathrm{aA}$ & $73,33 \mathrm{bcB}$ & $91,00 \mathrm{aA}$ & $91,33 \mathrm{aA}$ \\
\hline EMBRAPA 4 & $60,33 \mathrm{cdB}$ & $91,67 \mathrm{aA}$ & $92,00 \mathrm{aA}$ & $63,67 \mathrm{cB}$ & $91,00 \mathrm{aA}$ & $94,33 \mathrm{aA}$ \\
\hline EMGOPA 304 & $76,67 \mathrm{bcB}$ & $95,00 \mathrm{aA}$ & $85,67 \mathrm{aB}$ & $85,67 \mathrm{abB}$ & $96,33 \mathrm{aA}$ & $92,67 \mathrm{aAB}$ \\
\hline Rainha & $94,00 \mathrm{aA}$ & $96,33 \mathrm{aA}$ & $93,00 \mathrm{aA}$ & $95,00 \mathrm{aA}$ & $96,00 \mathrm{aA}$ & $93,67 \mathrm{aA}$ \\
\hline Itiquira & $56,67 \mathrm{~dB}$ & $90,33 \mathrm{aA}$ & $91,67 \mathrm{aA}$ & $69,00 \mathrm{cB}$ & $89,33 \mathrm{aA}$ & $94,33 \mathrm{aA}$ \\
\hline
\end{tabular}

${ }^{1}$ Dentro de cada variável, médias na mesma linha seguidas pela mesma letra maiúscula, ou na mesma coluna seguidas pela mesma letra minúscula, não diferem entre si pelo teste de Tukey, a $5 \%$ de probabilidade.

2 Coeficiente de variação quanto à cultivar, $6,64 \%$ e quanto à época, $7,18 \%$.

3 Coeficiente de variação quanto à cultivar, $5,76 \%$ e quanto à época, $5,46 \%$.

TABELA 2. Valores médios de porcentagem de sementes vigorosas discriminadas pelo teste de tetrazólio e produzidas por sete cultivares precoces de soja, a partir de três épocas de semeadura, na região de Goiânia, GO' ${ }^{1}$.

\begin{tabular}{llll}
\hline Cultivares & \multicolumn{3}{c}{ Épocas de semeadura } \\
\cline { 2 - 4 } & $30 / 10 / 95$ & $20 / 11 / 95$ & \multicolumn{1}{c}{$30 / 12 / 95$} \\
\hline EMGOPA 316 & $46,67 \mathrm{bcB} B^{2}$ & $79,00 \mathrm{bcdA} A$ & $55,33 \mathrm{cB} M$ \\
EMGOPA 309 & $55,33 \mathrm{bA} M$ & $67,33 \mathrm{deA} M$ & $61,67 \mathrm{bcA} M$ \\
EMBRAPA 1 & $56,67 \mathrm{bB} M$ & $73,33 \mathrm{cdA} A$ & $67,33 \mathrm{abcAB} M$ \\
EMBRAPA 4 & $49,00 \mathrm{bcB} B$ & $86,33 \mathrm{abcA} M A$ & $59,67 \mathrm{bcB} M$ \\
EMGOPA 304 & $61,33 \mathrm{bB} M$ & $89,67 \mathrm{abA} M A$ & $71,33 \mathrm{abcB} A$ \\
Rainha & $84,33 \mathrm{aAB} M A$ & $91,33 \mathrm{aA} M A$ & $78,00 \mathrm{aB} A$ \\
Itiquira & $33,00 \mathrm{cC} B$ & $52,33 \mathrm{eB} M$ & $73,67 \mathrm{abA} A$ \\
\hline
\end{tabular}

${ }^{1}$ Médias na mesma coluna seguidas pela mesma letra minúscula, ou na mesma linha seguidas pela mesma letra maiúscula, não diferem entre si, a 5\% de probabilidade, pelo teste de Tukey; letras maiúsculas em itálico indicam o respectivo nível de vigor, segundo a classificação proposta por França Neto (1994), a saber: $B=$ baixo, $M=$ médio, $A=$ alto e $M A=$ muito alto; coeficiente de variação quanto à cultivar, $7,16 \%$ e quanto à época, 7,43\% . 
Itiquira, e seriamente restritivos no que se refere às demais cultivares, talvez em decorrência da colheita e menor umidade das sementes, em período seco (Fig. 3). Segundo Hamer \& Peske (1997), as sementes entre $14 \%$ e $18 \%$ de umidade apresentam menor incidência de danos mecânicos, menores perdas na colheita, e maior germinação e vigor.
Os danos totais por condições adversas de umidade foram geralmente maiores nas sementes oriundas da semeadura antecipada para outubro, e as cultivares Rainha e EMGOPA 309 apresentaram danos menores. Nas sementes provenientes das semeaduras de novembro e dezembro, os danos foram superficiais, não causando a sua inviabilidade ou restri-

TABELA 3. Incidência de danos mecânicos totais e letais avaliados pelo teste de tetrazólio, em sementes produzidas por sete cultivares precoces de soja, a partir de três épocas de semeadura, na região de Goiânia, GO'1.

\begin{tabular}{|c|c|c|c|c|c|c|}
\hline \multirow[t]{2}{*}{ Cultivares } & \multicolumn{3}{|c|}{ Sementes com danos mecânicos totais $(\%)^{2}$} & \multicolumn{3}{|c|}{ Sementes com danos mecânicos letais $(\%)^{3}$} \\
\hline & $30 / 10 / 95$ & $20 / 11 / 95$ & $30 / 12 / 95$ & $30 / 10 / 95$ & $20 / 11 / 95$ & $30 / 12 / 95$ \\
\hline EMGOPA 316 & $68,67 \mathrm{aA}$ & $37,00 \mathrm{abB}$ & $65,33 \mathrm{aA}$ & $11,33 \mathrm{bcA}$ & $2,67 \mathrm{bcB}$ & $22,67 \mathrm{abA}$ \\
\hline EMGOPA 309 & $63,33 \mathrm{aA}$ & $42,33 \mathrm{aB}$ & $70,00 \mathrm{aA}$ & $14,33 \mathrm{abcB}$ & $13,00 \mathrm{aB}$ & $34,67 \mathrm{aA}$ \\
\hline EMBRAPA 1 & $65,67 \mathrm{aA}$ & $35,33 \mathrm{abB}$ & $58,67 \mathrm{abA}$ & $24,67 \mathrm{abA}$ & $3,67 \mathrm{abcB}$ & $13,67 \mathrm{bcA}$ \\
\hline EMBRAPA 4 & $58,67 \mathrm{aA}$ & $33,33 \mathrm{abB}$ & $65,33 \mathrm{aA}$ & $13,67 \mathrm{bcA}$ & $4,33 \mathrm{bcB}$ & $20,67 \mathrm{abA}$ \\
\hline EMGOPA 304 & $54,67 \mathrm{aA}$ & $31,67 \mathrm{abB}$ & $65,67 \mathrm{aA}$ & $6,33 \mathrm{cdAB}$ & $3,67 \mathrm{abcB}$ & $13,67 \mathrm{bcA}$ \\
\hline Rainha & $31,00 \mathrm{bAB}$ & $21,33 \mathrm{bB}$ & $42,33 \mathrm{bA}$ & $0,67 \mathrm{~dB}$ & $1,00 \mathrm{cB}$ & $7,33 \mathrm{cA}$ \\
\hline Itiquira & $71,00 \mathrm{aA}$ & $48,00 \mathrm{aB}$ & $41,67 \mathrm{bB}$ & $28,00 \mathrm{aA}$ & $9,33 \mathrm{abB}$ & $8,00 \mathrm{cB}$ \\
\hline
\end{tabular}

TABELA 4. Incidência de danos totais e letais por umidade avaliados pelo teste de tetrazólio, em sementes produzidas por sete cultivares precoces de soja, a partir de três épocas de semeadura, na região de Goiânia, GO' ${ }^{1}$.

\begin{tabular}{|c|c|c|c|c|c|c|}
\hline \multirow[t]{2}{*}{ Cultivares } & \multicolumn{3}{|c|}{ Sementes com danos totais por unidade $(\%)^{2}$} & \multicolumn{3}{|c|}{ Sementes com danos letais por unidade (\%) } \\
\hline & $30 / 10 / 95$ & $20 / 11 / 95$ & $30 / 12 / 95$ & $30 / 10 / 95$ & $20 / 11 / 95$ & $30 / 12 / 95$ \\
\hline EMGOPA 316 & $63,67 \mathrm{aA}$ & $10,67 \mathrm{cdB}$ & $10,33 \mathrm{bB}$ & 6,67 & 0,33 & 1,67 \\
\hline EMGOPA 309 & $21,33 \mathrm{cA}$ & $8,00 \mathrm{deB}$ & $7,67 \mathrm{bB}$ & 0,33 & 0,00 & 1,33 \\
\hline EMBRAPA 1 & $39,67 \mathrm{bA}$ & $20,33 \mathrm{bcB}$ & $1,00 \mathrm{cC}$ & 3,33 & 0,67 & 0,00 \\
\hline EMBRAPA 4 & $35,33 \mathrm{bcA}$ & $22,44 \mathrm{bB}$ & $27,67 \mathrm{aAB}$ & 1,67 & 0,00 & 7,00 \\
\hline EMGOPA 304 & $28,33 \mathrm{bcA}$ & $7,67 \mathrm{deB}$ & $7,33 \mathrm{bB}$ & 2,33 & 0,00 & 1,33 \\
\hline Rainha & $23,67 \mathrm{cA}$ & $2,00 \mathrm{eB}$ & $1,33 \mathrm{cB}$ & 0,00 & 0,00 & 0,00 \\
\hline Itiquira & $29,33 \mathrm{bcB}$ & $52,67 \mathrm{aA}$ & $1,00 \mathrm{cC}$ & 7,00 & 0,33 & 0,00 \\
\hline
\end{tabular}

1 Dentro de cada variável, médias na mesma linha seguidas pela mesma letra maiúscula, ou na mesma coluna seguidas pela mesma letra minúscula, não diferem entre si pelo teste de Tukey, a 5\% de probabilidade.

2 Coeficiente de variação quanto à cultivar, $14,61 \%$ e quanto à época, $14,65 \%$. 
ção à sua produção. Os danos letais por umidade constituíram restrição para a produção de sementes apenas das cultivares EMGOPA 316 e Itiquira quando semeadas em outubro.

Nas condições do Estado do Paraná, Menon et al. (1993) concluíram que o alto grau de deterioração ocasionado por fatores climáticos adversos, entre os pontos de maturação fisiológica e de colheita, afetam a qualidade das sementes. Também no Estado do Paraná, Costa et al. (1994) constataram que as regiões mais propícias à produção de sementes apresentam temperaturas mais amenas $\left(<22^{\circ} \mathrm{C}\right)$ durante a fase de maturação, pois favorecem a produção de sementes de qualidades fisiológica e sanitária superiores, e que a deterioração por umidade e danos mecânicos são os principais fatores que contribuem para a redução da qualidade das sementes de cultivares de soja de ciclo precoce. Semelhantes constatações foram também registradas por França Neto \& Henning (1992).

No Estado de Mato Grosso, Costa et al. (1995), mesmo trabalhando com cultivares de soja de ciclo tardio, encontraram danos expressivos causados por condições adversas de umidade, quando a semeadura foi antecipada para outubro. Segundo os autores, o baixo poder germinativo e o baixo vigor observados nessas sementes foram causados pela exposição da lavoura a condições climáticas desfavoráveis de temperatura e umidade.
A incidência de Phomopsis sojae e Fusarium spp. nas sementes produzidas pelas cultivares a partir das três épocas de semeadura pode ser vista na Tabela 5. Observa-se, em geral, maior porcentagem de sementes infectadas por Phomopsis sojae, quando a semeadura foi antecipada para outubro. Nessa época de semeadura, a cultivar Rainha produziu sementes com menor incidência pelo fungo (6\%), enquanto as demais cultivares apresentaram valores muito altos de porcentagem de sementes infectadas (de $12 \%$ a 20\%). A alta incidência de Phomopsis sojae, aliada à alta ocorrência de danos mecânicos (Tabela 3) e de danos causados por condições adversas de umidade (Tabela 4) podem ser apontadas como as causas do médio a baixo vigor das sementes produzidas pelas cultivares, exceto a Rainha, na semeadura antecipada em outubro (Tabela 2). Na semeadura convencional em novembro, as cultivares EMGOPA 316 e EMGOPA 309 ainda apresentaram cerca de $15 \%$ das sementes contaminadas pelo fungo, porém, com nível de vigor mais elevado, pela menor incidência de danos mecânicos e de danos causados por condições adversas de umidade.

Passos (1994), trabalhando em Minas Gerais, com duas variedades e 14 linhagens de soja, constatou que as altas temperaturas e umidade elevada favoreceram a incidência de fungos, especialmente Phomopsis spp., prejudicando a qualidade das sementes. Quando a incidência de Phomopsis spp. e o

TABELA 5. Incidência de Phomopsis sojae e Fusarium spp. em sementes produzidas por sete cultivares precoces de soja, a partir de três épocas de semeadura, na região de Goiânia, GO.

\begin{tabular}{|c|c|c|c|c|c|c|}
\hline \multirow[t]{2}{*}{ Cultivares } & \multicolumn{3}{|c|}{ Sementes infectadas por Phomopsis sojae (\%) } & \multicolumn{3}{|c|}{ Sementes infectadas por Fusarium spp. (\%) } \\
\hline & $30 / 10 / 95$ & $20 / 11 / 95$ & $30 / 12 / 95$ & $30 / 10 / 95$ & $20 / 11 / 95$ & $30 / 12 / 95$ \\
\hline EMGOPA 316 & 19,00 & 15,00 & 3,67 & 0,67 & 5,00 & 2,33 \\
\hline EMGOPA 309 & 12,00 & 15,33 & 1,67 & 5,00 & 2,67 & 3,67 \\
\hline EMBRAPA 1 & 18,67 & 1,67 & 3,67 & 8,67 & 3,67 & 0,00 \\
\hline EMBRAPA 4 & 11,67 & 6,67 & 2,33 & 7,33 & 9,33 & 1,50 \\
\hline EMGOPA 304 & 17,70 & 3,00 & 5,67 & 1,67 & 4,33 & 1,33 \\
\hline Rainha & 6,00 & 1,50 & 2,00 & 0,33 & 2,67 & 1,00 \\
\hline Itiquira & 20,00 & 4,33 & 7,00 & 9,67 & 0,66 & 2,00 \\
\hline
\end{tabular}


total de fungos atingiram $25 \%$ e $47 \%$, respectivamente, a germinação caiu para $62 \%$.

Maior incidência de Phomopsis spp. e menores valores de germinação e vigor foram também encontrados por Paolinelli et al. (1984), em Uberaba, MG, em sementes provenientes de cultivo em outubro. Segundo os autores, sementes de boa qualidade e sanidade satisfatória foram obtidas nas semeaduras de novembro e dezembro. Nunes Júnior (1984), trabalhando com cultivares de ciclo tardio, no Estado de Goiás, constatou diferenças significativas entre cultivares quanto à qualidade sanitária das sementes produzidas e apontou a época de 19/11 como a mais apropriada para a produção de sementes.

A incidência de Fusarium spp. nas sementes foi bem menor que a de Phomopsis sojae, em todas as cultivares e épocas de semeadura. No entanto, esse fungo pode também ter contribuído para a redução da germinação e vigor das sementes das cultivares, exceto da Rainha, principalmente quando associado aos elevados danos mecânicos e por umidade. Segundo Henning (1987) e França Neto \& Henning (1992), o Fusarium spp. também pode causar danos à germinação das sementes, e seus efeitos podem somar-se aos do Phomopsis sojae. Entre as diversas espécies de Fusarium relatadas, F. semitectum é a mais comum em sementes de soja no Brasil, e pode afetar a germinação no teste-padrão em laboratório, de modo semelhante ao Phomopsis spp.
A incidência de Cercospora kikuchii e Colletotrichum dematium nas sementes pode ser vista na Tabela 6. Em geral, altas porcentagens de sementes infectadas por Cercospora kikuchii foram constatadas em todas as cultivares, porém esse fungo não tem sido apontado na literatura como agente causal de danos relevantes às sementes de soja e sua germinação (Henning, 1987; França Neto \& Henning, 1992; Patrício et al., 1995). Por outro lado, a incidência de Colletotrichum dematium nas sementes produzidas pelas cultivares foi praticamente desprezível, nas três épocas de semeadura, exceto para a cultivar Itiquira, quando semeada em outubro, que apresentou $10 \%$ das sementes infectadas pelo fungo. Segundo Tiffany \& Neergard, citados por Henning (1987), esse fungo pode causar deterioração da semente, morte das plântulas e infecção sistêmica em plantas adultas. Assim, na semeadura em outubro, o fungo pode ter contribuído para a redução da germinação e do vigor das sementes produzidas pela cultivar Itiquira.

Finalmente, deve-se destacar que os resultados de germinação, vigor e sanidade das sementes obtidos neste trabalho e os obtidos por Nunes Júnior (1984) estão de acordo com as recomendações de semeadura de soja no mês de novembro, feitas pela Embrapa (1996).

TABELA 6. Incidência de Cercospora kikuchii e Colletotrichum dematium em sementes produzidas por sete cultivares precoces de soja, a partir de três épocas de semeadura, na região de Goiânia, GO.

\begin{tabular}{lccccccc}
\hline Cultivares & \multicolumn{3}{c}{$\begin{array}{c}\text { Sementes infectadas } \\
\text { por Cercospora kikuchii }(\%)\end{array}$} & & \multicolumn{3}{c}{$\begin{array}{c}\text { Sementes infectadas } \\
\text { por Colletotrichum dematium }(\%)\end{array}$} \\
\cline { 2 - 3 } \cline { 7 - 8 } & $30 / 10 / 95$ & $20 / 11 / 95$ & $30 / 12 / 95$ & & $30 / 10 / 95$ & $20 / 11 / 95$ & $30 / 12 / 95$ \\
\hline EMGOPA 316 & 27,00 & 36,00 & 24,30 & & 0,00 & 0,33 & 0,33 \\
EMGOPA 309 & 33,00 & 58,67 & 25,67 & & 0,67 & 1,00 & 0,00 \\
EMBRAPA 1 & 33,67 & 50,33 & 52,00 & & 2,67 & 0,00 & 1,00 \\
EMBRAPA 4 & 49,33 & 48,00 & 38,00 & & 3,00 & 3,00 & 1,67 \\
EMGOPA 304 & 54,67 & 56,67 & 46,33 & & 0,33 & 0,33 & 1,00 \\
Rainha & 16,00 & 39,00 & 28,00 & & 0,33 & 0,33 & 0,00 \\
Itiquira & 26,00 & 33,33 & 35,67 & & 10,00 & 2,00 & 0,67 \\
\hline
\end{tabular}




\section{CONCLUSÕES}

1. A qualidade fisiológica e sanitária das sementes é influenciada pelas cultivares e pelas épocas de semeadura.

2. A qualidade das sementes produzidas na semeadura antecipada para o final de outubro é afetada pela deterioração causada por condições adversas de umidade e por danos mecânicos, aliados à incidência de patógenos, especialmente Phomopsis sojae, enquanto na semeadura retardada para o final de dezembro é afetada por danos mecânicos.

\section{REFERÊNCIAS}

BHERING, M.C. Influência de épocas de plantio sobre algumas características agronômicas e qualidade das sementes de soja [Glycine $\max (\mathrm{L}$.) Merril]. Viçosa : UFV, 1989. 57p. Dissertação de Mestrado.

COSTA, N.P.; FRANÇA NETO, J. de B.; HENNING, A.A.; KRZYZANOWSKI, F.C.; CABRAL, N.T.; MENDES, E.M.C. Efeito da época de semeadura sobre a qualidade fisiológica de sementes de soja no Estado do Mato Grosso. Revista Brasileira de Sementes, Brasília, v.17, n.1, p.107-112, 1995.

COSTA, N.P.; PEREIRA, L.A.G.; FRANÇA NETO, J. de B.; HENNING, A.A.; KRZYZANOWSKI, F.C. Zoneamento ecológico do Estado do Paraná para a produção de sementes de cultivares precoces de soja. Revista Brasileira de Sementes, Brasília, v.16, n.1, p.12-19, 1994.

EMBRAPA. Centro Nacional de Pesquisa de Soja (Londrina, PR). Recomendações técnicas para a cultura da soja na região central do Brasil-1996/97. Londrina: Embrapa-CNPSo, 1996. 164p. (EmbrapaCNPSo. Documentos, 96).

FRANÇA NETO, J. de B. O teste de tetrazólio em sementes de soja. In: VIEIRA, R.D.; CARVALHO, N.M. de. Testes de vigor em sementes. Jaboticabal : FUNEP, 1994. p.87-102.

FRANÇA NETO, J. de B.; HENNING, A.A. DIACOM: diagnóstico completo da qualidade da semente de soja. Londrina : Embrapa-CNPSo, 1992. 21p. (Embrapa-CNPSo. Circular Técnica, 10).

FRANÇA NETO, J. de B.; KRZYZANOWSKI, F.C.; HENNING, A.A. Teste de tetrazólio e patologia de sementes como instrumentos fundamentais na produção de sementes de soja. Anuário ABRASEM, Brasília, p.16-18, 1990.

Pesq. agropec. bras., Brasília, v.35, n.8, p.1653-1662, ago. 2000
HAMER, E.; PESKE, S.T. Colheita de sementes de soja com alto grau de umidade. I. Qualidade física. Revista Brasileira de Sementes, Brasília, v.19, n.1, p.106-110, 1997.

HENNING, A.A. Testes de sanidade de sementes de soja. In: SOAVE, J.; WETZEL, M.M.V.S. (Ed.). Patologia de sementes. Campinas : Fundação Cargill, 1987. p.441-454.

KRZYZANOWSKI, F.C.; GILIOLI, J.L.; MIRANDA, L.C. Produção de sementes nos cerrados. In: ARANTES, N.E.; SOUZA, P.I. de M. de (Ed.). Cultura da soja nos cerrados. Piracicaba : Potafos, 1993. p.465-522.

MAURO, A.O.; SEDIYAMA, T.; SEDIYAMA, C.S. Estimativas de parâmetros genéticos em diferentes tipos de parcelas experimentais em soja. Pesquisa Agropecuária Brasileira, Brasília, v.30, n.5, p.667672, maio 1995.

MENON, J.C.M.; BARROS, A.C.S.A.; MALLO, V.D.C.; ZONTA, E.P. Avaliação da qualidade física e fisiológica da semente de soja produzida no Estado do Paraná, na safra 1989/90. Revista Brasileira de Sementes, Brasília, v.15, n.2, p.203-208, 1993.

NUNES JÚNIOR, J. Efeito do genótipo e da época de semeadura na sanidade de soja [Glycine $\max (\mathrm{L}$.) Merrill] no Estado de Goiás. Viçosa : UFV, 1984. 144p. Dissertação de Mestrado.

PAOLINELLI, G.P.; TANAKA, M.A.S.; REZENDE, A.M. Influência da época de semeadura sobre a qualidade fisiológica e sanitária de sementes de soja. Revista Brasileira de Sementes, Brasília, v.6, n.1, p.39-50, 1984.

PASSOS, G.A. Avaliação de caracteres agronômicos e de qualidades fisiológica e sanitárias das sementes de genótipos de soja [Glycine $\max (\mathrm{L}$.) Merril] cultivados em diferentes regiões de Minas Gerais. Viçosa : UFV, 1994. 91p. Dissertação de Mestrado.

PATRÍCIO, F.R.A.; BORIN, R.B.R.G.; ORTOLANI, D.B. Patógenos associados a sementes que reduzem a germinação e vigor. In: MENTEN, J.O. (Ed.). Patógenos em sementes: detecção, danos e controle químico. São Paulo : Ciba Agro, 1995. p.137-160.

PIMENTEL-GOMES, F. A Estatística moderna na pesquisa agropecuária. Piracicaba : Potafos, 1984. $160 \mathrm{p}$.

URBEN FILHO, G.; SOUZA, P.I. de M. de. Manejo da cultura da soja no Cerrado: época, densidade e profundidade de semeadura. In: ARANTES, N.E.; SOUZA, P.I. de M. de (Ed.). Cultura da soja nos cerrados. Piracicaba : Potafos, 1993. p.267-298. 